\title{
Genome-Wide Identification and Characterization of Cucumber BPC Transcription Factors and Their Responses to Abiotic Stresses and Exogenous Phytohormones
}

\author{
Shuzhen Li ${ }^{1,2}$, Li Miao ${ }^{1}$, Bin Huang ${ }^{1}$, Lihong Gao ${ }^{2}$, Chaoxing He ${ }^{1}$, Yan Yan ${ }^{1}$, Jun Wang ${ }^{1}$, \\ Xianchang $\mathrm{Yu}^{1, *}$ and Yansu $\mathrm{Li}^{1, *}$ \\ 1 Institute of Vegetables and Flowers, Chinese Academy of Agricultural Sciences, Beijing 100081, China; \\ limengfbj@126.com (S.L.); happymml@163.com (L.M.); 82101175049@caas.cn (B.H.); \\ hechaoxing@caas.cn (C.H.); yanyan@caas.cn (Y.Y.); wangjun01@caas.cn (J.W.) \\ 2 Beijing Key Laboratory of Growth and Developmental Regulation for Protected Vegetable Crops, \\ College of Horticulture, China Agricultural University, Beijing 100193, China; gaolh@cau.edu.cn \\ * Correspondence: yuxianchang@caas.cn (X.Y.); liyansu@caas.cn (Y.L.)
}

Received: 20 August 2019; Accepted: 2 October 2019; Published: 11 October 2019

\begin{abstract}
BASIC PENTACYSTEINE (BPC) is a small transcription factor family that functions in diverse growth and development processes in plants. However, the roles of BPCs in plants, especially cucumber (Cucumis sativus L.), in response to abiotic stress and exogenous phytohormones are still unclear. Here, we identified four BPC genes in the cucumber genome, and classified them into two groups according to phylogenetic analysis. We also investigated the gene structures and detected five conserved motifs in these CsBPCs. Tissue expression pattern analysis revealed that the four CsBPCS were expressed ubiquitously in both vegetative and reproductive organs. Additionally, the transcriptional levels of the four CsBPCs were induced by various abiotic stress and hormone treatments. Overexpression of CsBPC2 in tobacco (Nicotiana tabacum) inhibited seed germination under saline, polyethylene glycol, and abscisic acid (ABA) conditions. The results suggest that the CsBPC genes may play crucial roles in cucumber growth and development, as well as responses to abiotic stresses and plant hormones. CsBPC2 overexpression in tobacco negatively affected seed germination under hyperosmotic conditions. Additionally, CsBPC2 functioned in ABA-inhibited seed germination and hypersensitivity to ABA-mediated responses. Our results provide fundamental information for further research on the biological functions of BPCs in development and abiotic stress responses in cucumber and other plant species.
\end{abstract}

Keywords: BASIC PENTACYSTEINE (BPC); cucumber; expression analysis; abiotic stress; plant hormones

\section{Introduction}

Cucumber (Cucumis sativus L.) is a major vegetable crop worldwide and has served as a model system for studies on sex determination [1] and plant vascular biology [2]. However, its growth and development are frequently affected by various stresses, such as low temperature [3], high salinity [4,5], water deficit [6], and pathogen attack [7], which severely reduce production and quality. Therefore, functional studies of cucumber stress responses and identification of stress-related genes are required to elucidate the molecular mechanisms of cucumber stress tolerance and protect them from detrimental surroundings. 
BASIC PENTACYSTEINE (BPC)/BARLEY B RECOMBINANT (BBR), a plant-specific transcription factor family, is characterized by the ability to bind gene promoter sequences at the GAGA motif; the soybean GAGA-binding protein $(\mathrm{GBP})$ binds to a $(\mathrm{GA})_{9}$ repeat sequence of the Glutamate 1-Semialdehyde Aminotransferase (Gsa1) promoter [8], the barley BARLEY B RECOMBINANT (BBR) factor binds specifically to the (GA) 8 repeat in vitro [9], and Arabidopsis BPC proteins recognize (GA) 6 and $(\mathrm{GA})_{9}$ sequences $[10,11]$. According this characteristic, BPC transcription factors are also named GAGA-binding transcriptional activators. To date, based on gene sequence similarity and protein domain structures, seven Arabidopsis BPC genes have been identified and classified into three classes: class I (BPC1-3), class II (BPC4-6), and class III (BPC7). All of the BPC proteins contain a highly conserved DNA-binding domain with five conserved cysteine residues at their $C$ terminus [10]. Among these genes, BPC 5 is thought to be a pseudogene that is unable to produce an active protein $[10,12]$.

As newly identified transcription factors, BPCs have been proposed to function in diverse plant growth and development responses. For example, transcripts of the barley BBR gene were detected in all tissues, including roots, stems, leaves, inflorescences, and embryos, among which the highest level was observed in embryos and the lowest in leaves. Overexpression of the gene in tobacco resulted in pronounced leaf and flower shapes or structural modifications [9]. In Arabidopsis, all seven BPC genes except for $B P C 5$ were expressed ubiquitously in both vegetative and reproductive organs. Multiple $B P C$ allele mutants displayed pleiotropic developmental defects, including dwarfism, small rosettes, early flowering, aberrant ovules, unopened floral buds, and even high sterility [12-15]. The reason for these morphological changes may be that BPCs bind to and regulate the activities and expression levels of target genes associated with development. BPC genes have been reported to be regulators of INNER NO OUTER (INO), a gene involved in ovule development [10]. BPC genes were also found to regulate the expression of the homeotic MADS box gene SEEDSTICK (STK), to control the ovule identity $[11,13,16,17]$. The LEAFY COTYLEDON 2 (LEC2) gene is only expressed in embryos and acts as a master regulator of seed development, and is regulated by BPCs in Arabidopsis [18-20]. Additionally, BPCs downregulated the expression of the genes SHOOTMERISTEMLESS (STM) and BREVIPEDICELLUS/KNAT1 (BP), which resulted in floral organ malformation [14]. Additionally, class I BPCs also act as direct regulators of several HOMEOBOX genes, such as KNOX, WUS, and BELL family members [14]. In our previous research, we found that cucumber BPCs are involved in seed germination as regulators of ABSCISIC ACID INSENSITIVE3 (ABI3) [21]. In rice, the GAGA-binding transcription factors $O s G B P 1$ and $O s G B P 3$ displayed functional divergence in the regulation of grain size and plant growth [22]. OsGBP1 also delayed flowering time by directly binding to the promoter of OsLFL1, a LEC2/FUS3-like gene, which constitutively inhibits the expression of a flowering activator, Early heading date 1 (Ehd1) [22-24]. Moreover, increasing evidence has also demonstrated a role for BPCs in the regulation of plant responses to hormones, such as ethylene [12] and cytokinins [14,25]. While BPCs are known to participate in numerous developmental processes, the involvement of BPCs in stress responses is not clear.

The completion of genome sequencing for more species has enabled many genes to be identified and characterized. However, comprehensive analyses of BPC genes in cucumber and other plant species are still limited. Thus, in the present study, we identified four BPC family members in the cucumber genome, named CsBPC1 to CsBPC4. They were classified into two groups based on phylogenetic analysis. Their predicted gene structures and conserved motifs were subsequently analyzed. Furthermore, we investigated their expression patterns in various tissues and in response to different stresses and plant hormones by qRT-PCR. To further verify the cellular functions of the CsBPCs, transgenic tobacco plants constitutively overexpressing CsBPC2 were generated and seed germination experiments with different concentrations of salt, polyethylene glycol (PEG), and abscisic acid (ABA) were conducted. This work provides a basis for exploring the potential functions of BPC genes, especially in stress resistance. This will enrich the stress tolerance theory of plants and lay a theoretical foundation to alleviate the detrimental effects on cucumber growth caused by various abiotic stresses. 


\section{Results}

\subsection{Identification and Characterization of Cucumber BPC Genes}

To identify BPC family genes in cucumber, we performed BLASTP searches against the Cucumber Genome Database using seven Arabidopsis BPC proteins as query sequences, and confirmed the candidate sequences using the Pfam and SMART databases. We detected four BPC family proteins containing the GAGA binding-like domain (Table 1), which was consistent with our previous identification [21]. However, here we found that Csa5G092920.2 and Csa7G007860.1 had two and three transcripts, respectively, and we selected genes with longest encoding protein sequences for subsequent analysis. Two of the four members were distributed on chromosome five; the other two were distributed on chromosomes two and seven, respectively (Figure 1). All proteins shared similar parameters. The amino acid lengths of these four genes ranged from 279 to 338 aa, with molecular weights ranging from 31.1 to $37.8 \mathrm{kDa}$. The isoelectric points of all four BPC proteins were relatively high ( $\mathrm{pI}>9$ ), indicating that they are rich in alkaline amino acids. Subcellular location prediction showed that all four members were localized to the nucleus.

Table 1. Characteristics of the BASIC PENTACYSTEINE (BPC) family in cucumber. Gene ID with black bold means more than one transcripts.

\begin{tabular}{|c|c|c|c|c|c|c|c|}
\hline Gene ID & Length (aa) & Molecular Weight (KD) & Chromosome & Location & pI & $\begin{array}{c}\text { Strand } \\
\text { Direction }\end{array}$ & $\begin{array}{l}\text { Subcellular } \\
\text { Location }\end{array}$ \\
\hline Csa2G365700.1 & 338 & 37.8 & 2 & $17669793-17673023$ & 9.52 & + & Nuclear \\
\hline Csa5G092910.1 & 279 & 31.1 & 5 & $2693816-2695298$ & 9.62 & - & Nuclear \\
\hline Csa5G092920.2 & 284 & 31.7 & 5 & $2696954-2700269$ & 9.84 & - & Nuclear \\
\hline Csa7G007860.1 & 313 & 35 & 7 & 388479-391899 & 9.6 & + & Nuclear \\
\hline
\end{tabular}

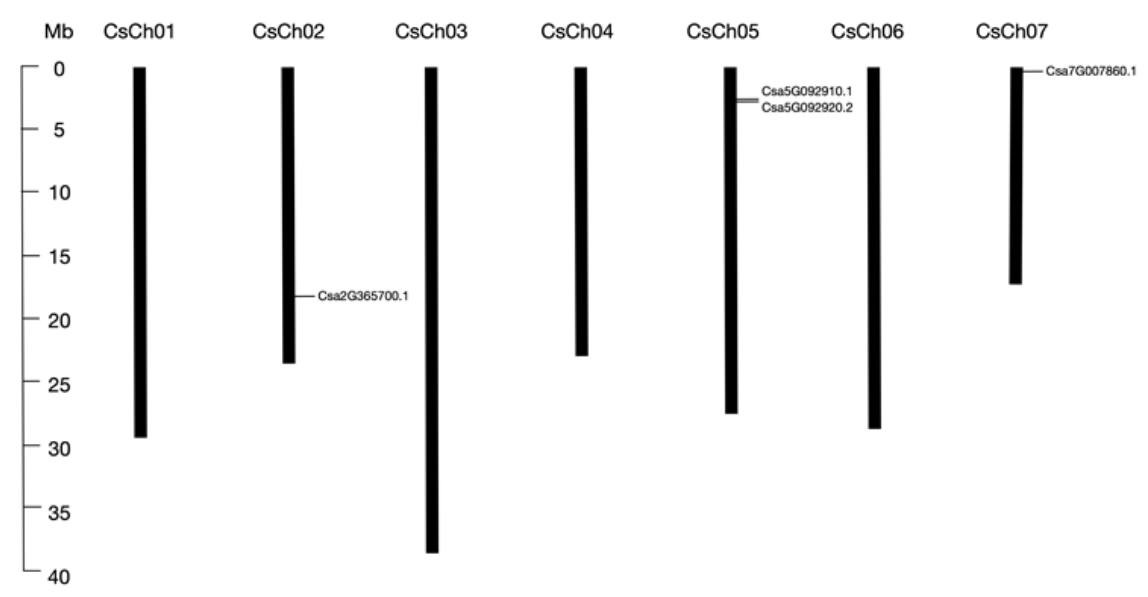

Figure 1. Localization of four cucumber BPC genes on chromosomes. There are seven chromosomes in cucumber, and the chromosome number is indicated at the top of each chromosome. The scale bar on the left side indicates the size of chromosome. The relative positions of four BPC genes are marked on the chromosomes.

\subsection{Phylogenetic Gene Structure and Motif Analysis}

To gain insight into the evolution of the BPCs in cucumber, a phylogenetic tree was constructed using BPC proteins from different plant species, including cucumber, watermelon, melon, cucurbita pepo, grape, western balsam poplar, common sunflower, Arabidopsis, rice and tomato. As shown in Figure 2, the 52 BPC proteins were classified into three groups, which was consistent with previous classification in Arabidopsis [10]. Csa5G092910.1 and Csa5G092920.2 belonged to group I; here, we named them CsBPC1 and CsBPC2, respectively. Csa7G007860.1 and Csa2G365700.1 belonged to group II; here, we named them CsBPC 3 and CsBPC4, respectively. The numbers of BPC genes in group I, group II, and group III were 24, 26, and 2, respectively. BPC genes in Arabidopsis and western balsam 
poplar were clustered in each group, whereas, those in other eight species were just clustered in group I and group II. This indicated that BPC genes in group I and group II were relatively more conserved than those in group III, and that BPC genes in group III might be lost more easily during the evolutionary process. Besides, since cucumber, watermelon, melon, and cucurbita pepo belong to the Cucurbitaceae family, their evolutionary processes were more similar with each other than that with other species. Moreover, each cucumber BPC gene was closest with that in melon. Figure 3A illustrates the exon-intron organizations of the CsBPC genes. All the CsBPC genes possessed one intron, with the exception of CsBPC1, which lacked an intron. Additionally, the introns of CsBPC3 and CsBPC4 were phase zero introns, while CsBPC2 had a phase two intron. The conserved domains of the CsBPC proteins were then analyzed and five conserved motifs were identified (Figure 3B). In general, members in the same group shared similar motif compositions, whereas members in different groups had differing motif compositions. Both group I members possessed four motifs, while both group II members had three motifs. Motifs one and two were found in all four members. Motifs three and five were only found in the group I members, and motif four only in the group II members. Furthermore, motif one contained five conserved cysteine residues (Figure 3C), which is the unique hallmark of the BPC transcription factor family $[10,11]$.

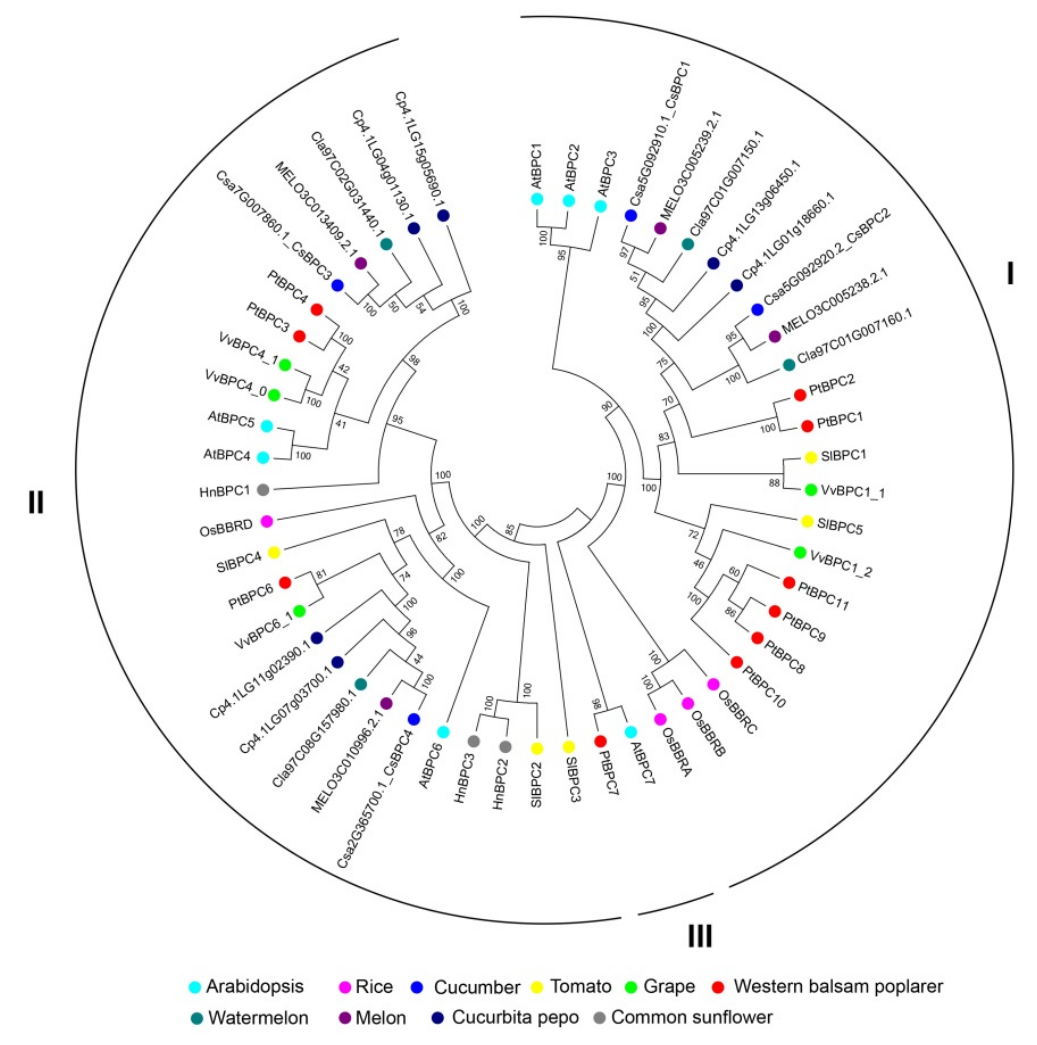

Figure 2. Phylogenetic analysis of BPC proteins from cucumber and other species. BPC polypeptide sequences generated from four cucumber, seven Arabidopsis, four rice, four watermelon, four melon, six cucurbita pepo, five grape, ten western balsam poplar, three common sunflower, and five tomato (SIBPCs) plants were used to construct an unrooted neighbor-joining phylogenetic tree by MEGA7 software with 100 bootstrap replicates. The different colored dots indicate different species. 


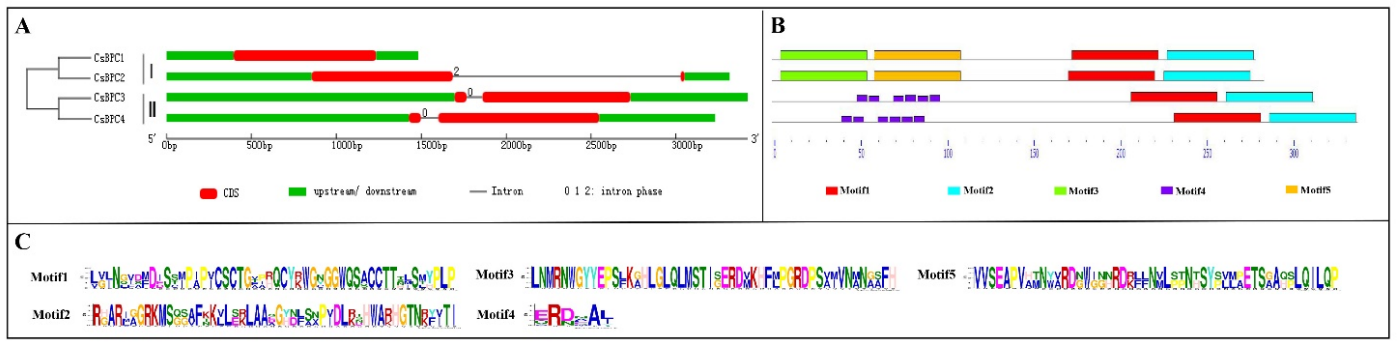

Figure 3. Gene structure and conserved motif analyses of cucumber BPC members. (A) Exon-intron organization of CsBPC genes. Red boxes represent exons and the black lines represent introns. The numbers 0,1 , and 2 represent the intron phases. The untranslated $5^{\prime}$ - and $3^{\prime}$ - regions (UTR) are shown with green boxes. (B) Conserved motif in cucumber BPC proteins. Five motifs with E-value $<0.05$ are presented with different colored boxes. (C) The sequences of five identified motifs in cucumber BPC proteins.

\subsection{Expression Profiles in Different Tissues}

To confirm the potential functions of the CsBPCs in cucumber growth and development, the expression patterns of the four CsBPC genes were analyzed by qRT-PCR in 12 different tissues. As shown in Figure 4, all four CsBPC genes were expressed to varying degrees in the tissues tested, and they shared the highest expression levels in seeds and the lowest levels in tendrils and stems. The expression levels of the CsBPCS in different floral organs, including male flowers (MF), female flowers with ovaries removed (FF), and ovaries (O), showed that $C s B P C 1, C s B P C 2$, and $C s B P C 3$ were highly expressed in ovaries compared with the other two organs, whereas CsBPC4 was expressed at almost the same level in all three organs. Additionally, when comparing the expression levels in leaves at different developmental stages, we found that $C s B P C 1$ and CsBPC4 had relatively higher transcription levels in young leaves than in mature and old leaves, which indicated that they may play an important role in the early stages of leaf growth and development. Collectively, the results indicated the CsBPC genes may play vital roles in many cellular processes in cucumber growth and development, and that the different members have overlapping but distinct functions. However, it is necessary to do plenty of complex experiments to investigate the functions of CsBPCs in regulating cucumber growth and development.

\subsection{Expression Patterns of the CsBPC Genes under Different Abiotic Stress and Phytohormone Treatments}

Increasing evidence suggests that BPC transcription factors play important roles in regulating plant growth and development. However, the involvement of BPCS in responses to abiotic stresses and phytohormones is not clear. To confirm the involvement of the CsBPCs in abiotic stress and hormone responses, their transcript abundances were investigated under $\mathrm{NaCl}, \mathrm{PEG}$, cold $\left(5^{\circ} \mathrm{C}\right)$, heat $\left(38^{\circ} \mathrm{C}\right), \mathrm{ABA}$, SA, JA, ETH, 2,4-D, and GA treatments. Overall, the expression of all four CsBPC genes was induced by all the treatments tested (Figures 5 and 6). For instance, under the $\mathrm{NaCl}$, PEG, and cold treatments, the expression levels of CSBPC2 in roots or leaves increased by a maximum of 6.1-, 6.1-, and 1.7-fold, respectively, the most among the four genes. Under heat stress, the transcript level of CsBPC4 was the highest at $12 \mathrm{~h}$ in roots (increased by 15.6-fold), followed by CsBPC2 in roots (increased by 14.0-fold). In response to the application of exogenous hormones, including ABA, GA, JA, and SA, the transcript levels of all four CsBPC genes, especially $C_{S} B P C 2$, in roots were dramatically induced with prolonged treatment, whereas the transcript levels in leaves were increased slightly. Additionally, the application of $\mathrm{ABA}$ more significantly induced gene expression in roots compared with the other three hormones. Notably, the expression level of CsBPC2 was increased by 112.1-fold after $24 \mathrm{~h}$ of ABA treatment. However, the expression patterns under ETH treatment were just the opposite, with higher gene expression induction in leaves than in roots. Lastly, application of 2,4-D highly induced the expression of all four genes in both roots and leaves, with maximal transcript levels at $12 \mathrm{~h}$ in leaves and $24 \mathrm{~h}$ in roots. Thus, the CsBPCs are involved in, and positively induced by, various abiotic stresses and phytohormones. 
CsBPC1
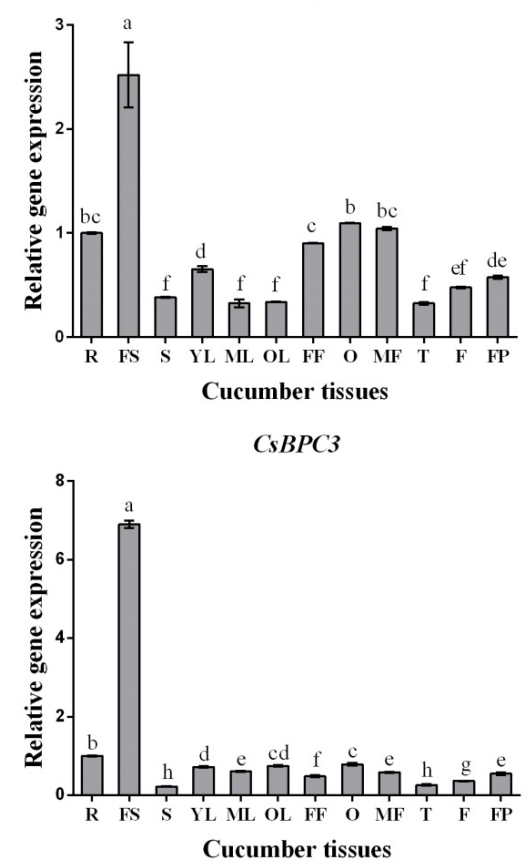

CsBPC2

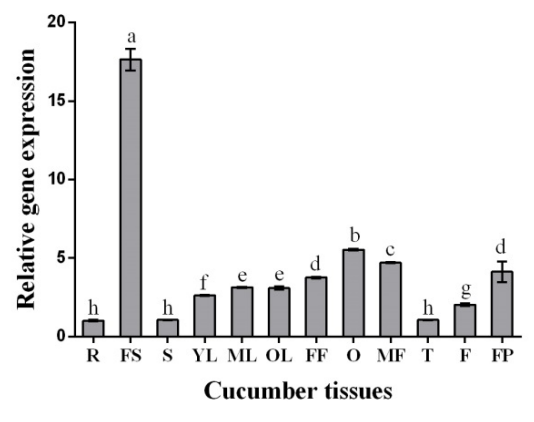

CsBPC4

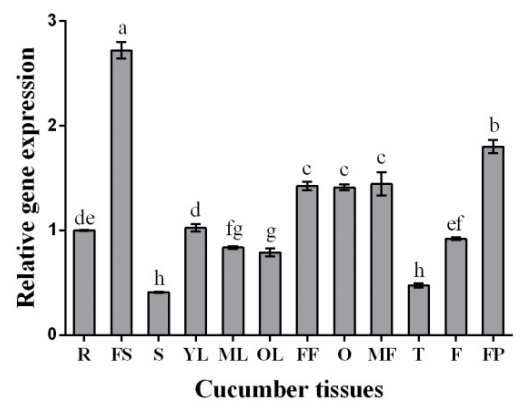

Figure 4. Expression analysis of CsBPC genes in different tissues. Transcript levels of CsBPCs were analyzed by qRT-PCR in roots (R), stems (S), top young leaves (YL), middle mature leaves (ML), basal old leaves (OL), blooming male flowers (MF), blooming female flowers with ovaries removed (FF), ovaries $(\mathrm{O})$, tendrils $(\mathrm{T})$, fruits $(\mathrm{F})$, mature fruits' seeds (FS), and pulps (FP). The expression levels of roots were defined as 1 . Values are means $\pm \operatorname{SD}(n=3)$. Different letters indicate significant differences $(p<0.05)$.
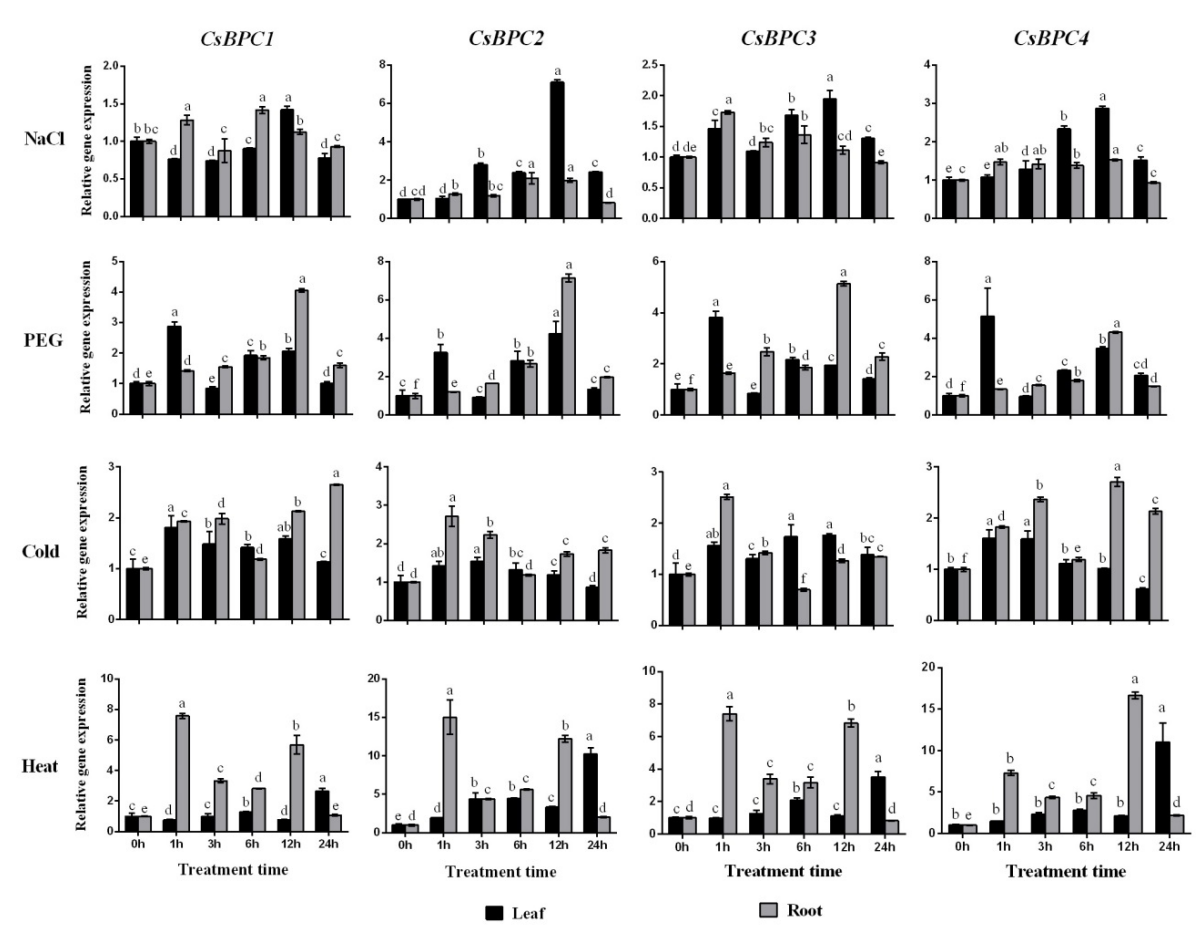

Figure 5. Expression patterns of CsBPC genes under different abiotic stress treatments. Cucumber seedlings at three-leaf-stage were exposed to $100 \mathrm{mM} \mathrm{NaCl}, 10 \%$ PEG 6000 , cold $\left(5^{\circ} \mathrm{C}\right)$, and heat $\left(38^{\circ} \mathrm{C}\right)$ conditions, and qRT-PCR was performed to examine the transcript levels of CsBPCs in response to different abiotic stresses. The expression levels in non-stressed leaves and roots were set as 1 . Values are means $\pm \operatorname{SD}(n=3)$. Different letters indicate significant differences $(p<0.05)$. 
CsBPC1
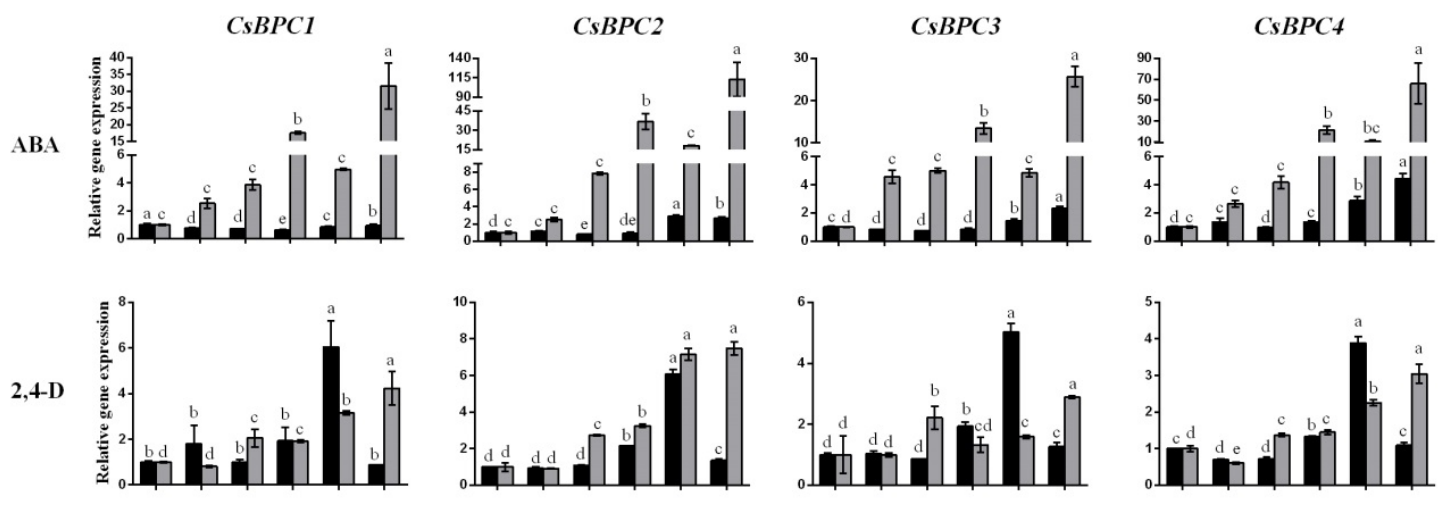

GA
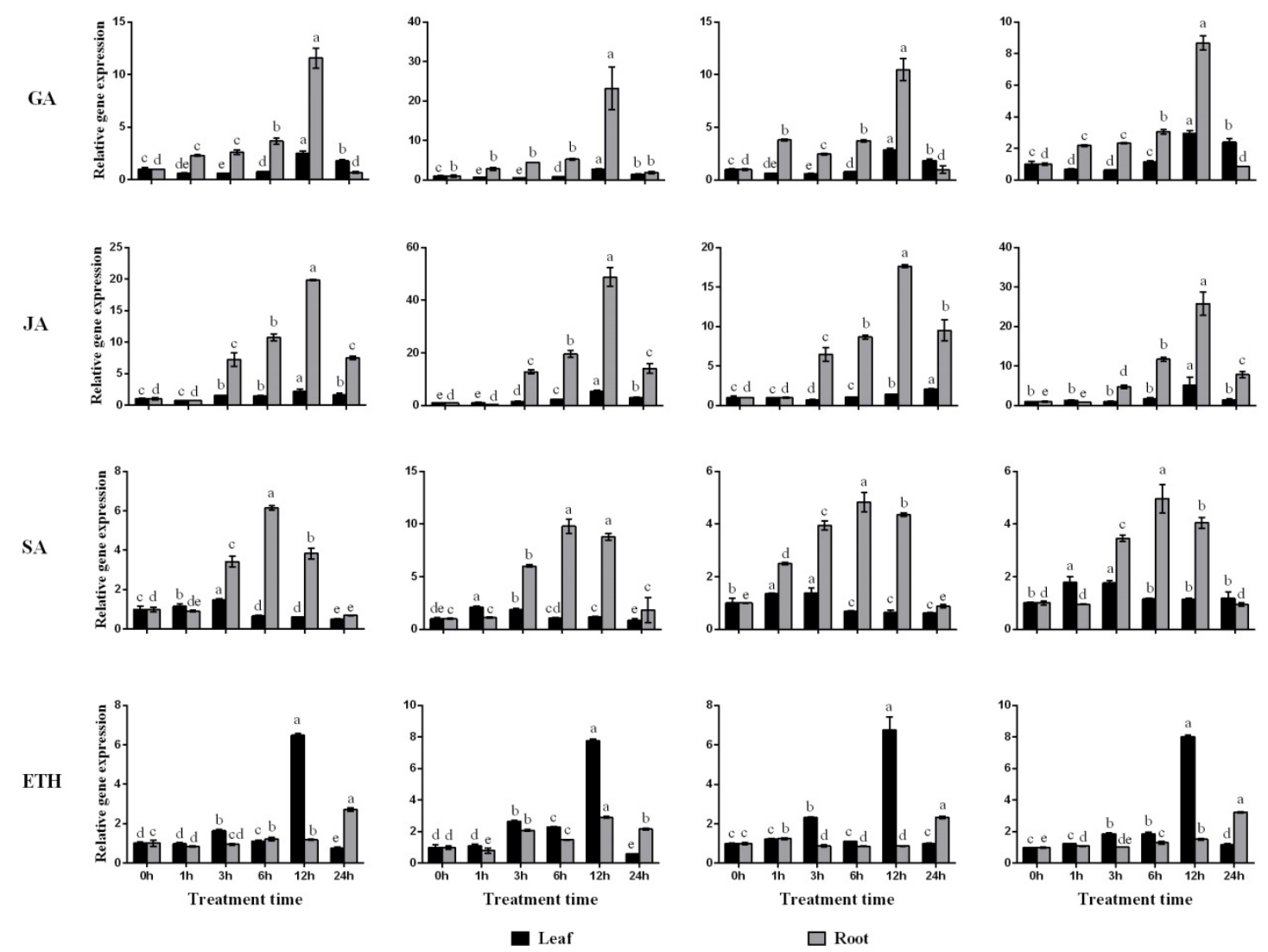

Figure 6. Expression patterns of CsBPC genes under different phytohormone treatments. Cucumber seedlings at three-leaf-stage were exposed to ABA, SA, JA, ETH, 2,4-D, and GA conditions, and qRT-PCR was performed to examine the transcript levels of CsBPCs in response to different phytohormones. The expression levels in non-stressed leaves and roots were set as 1. Values are means $\pm \operatorname{SD}(n=3)$. Different letters indicate significant differences $(p<0.05)$.

\subsection{Germination Assays under Stress and ABA Treatments}

Due to the fact that the above results showed that $C s B P C$ expression was induced by various abiotic stresses and phytohormones, especially CsBPC2, whose expression level increased the most under the majority of treatments, a vector for constitutive overexpression of CsBPC2 was constructed and transferred into tobacco plants to further study the cellular functions mediated by CSBPC2 in response to environmental stresses and plant hormones. Genomic DNA of 10 independent T0 progeny transgenic tobacco lines $(1,2,3$, etc.) was extracted for PCR confirmation (Additional file 3 ). The results showed that CsBPC2 was successfully integrated into the tobacco genome. Additionally, qRT-PCR indicated that $C s B P C 2$ was highly expressed in the transgenic lines, but no expression was observed 
in wild-type (WT) plants (Additional file 3). Thus, we chose two highly expressing lines, 5 and 6, for further experiments.

To further verify the effects mediated by CsBPC2 in abiotic stresses and plant hormone responses, seeds of WT and CsBPC2-overexpression plants (OE) were sown on MS solid medium containing different concentrations of $\mathrm{NaCl}, \mathrm{PEG}$, and $\mathrm{ABA}$. As shown in Figure 7A,D, the germination times and rates of the WT and OE seeds displayed no difference when sown on MS medium. However, in the presence of $100 \mathrm{mM} \mathrm{NaCl}$, the germination of OE was slightly inhibited compared with the WT (Figure 7B,E). Under $200 \mathrm{mM} \mathrm{NaCl}$, the germination rates and times of all genotypes were significantly inhibited, but the transgenic lines were inhibited much more than the WT (Figure 7C,F). The seeds of T1-5 and T1-6 began to germinate at day 14, six days later than the WT, and their germination rates were just $2.67 \%$ and $4.67 \%$, respectively, while that of the WT was $70 \%$. On the last day of the treatment, the germination rates of T1-5 and T1- 6 were $48.0 \%$ and $56.67 \%$, respectively, which were significantly lower than that of the WT $(91.33 \%)$.

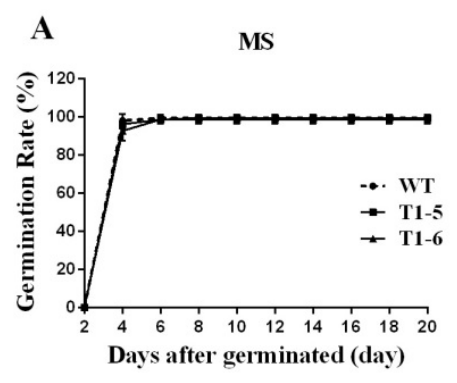

D

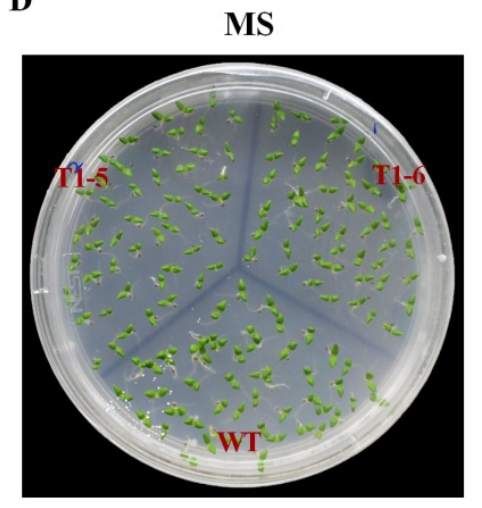

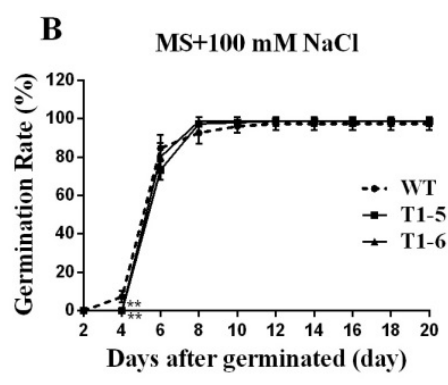

$\mathbf{E}$

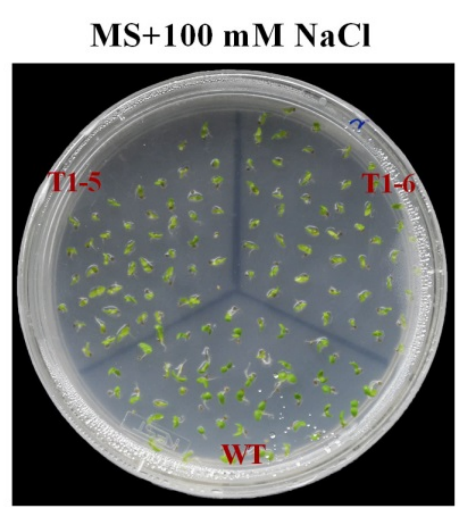

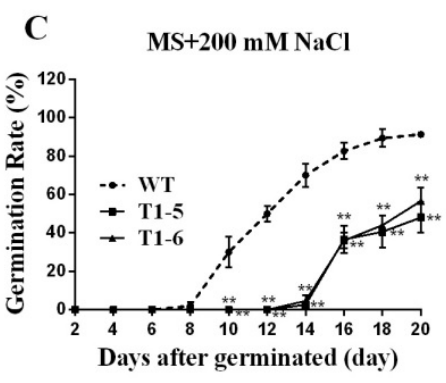

$\mathbf{F}$

F $\quad \mathrm{MS}+200 \mathrm{mM} \mathrm{NaCl}$

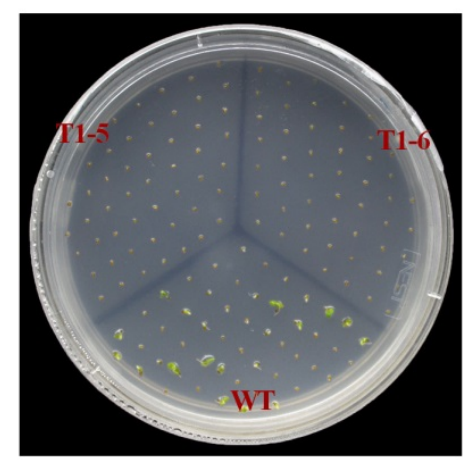

Figure 7. Effects of $\mathrm{NaCl}$ application on germination rates between wild-type (WT) and transgenic plants. Fifty seeds of WT and T1 transgenic plants were sown on sterile MS solid medium supplemented with different concentrations of $\mathrm{NaCl}(\mathbf{A}-\mathbf{C})$. Values are means $\pm \mathrm{SD}(n=3)$. The photographs $(\mathbf{D}, \mathbf{E})$ were taken after being sown for $9 \mathrm{~d}$, photograph $\mathbf{F}$ was taken after being sown for $13 \mathrm{~d} .{ }^{*}$ and ${ }^{* *}$ Significant at $p<0.05$ and $p<0.01$ compared with $\mathrm{WT}$, respectively.

In the presence of $10 \%$ PEG, although there was no difference in the final germination rates of the WT and OE seeds, the T1-5 and T1-6 seeds started to germinate at day eight, four days later than the WT, and their germination rates were $45.33 \%$ and $60.67 \%$, respectively, while that of the WT was $97.33 \%$ (Figure $8 \mathrm{~A}, \mathrm{C}$ ). Under 20\% PEG, the WT seeds started to germinate at day six, and the germination rate was $18.0 \%$, while T1-5 and T1-6 seeds started to germinate at day 10 and day eight, respectively, and their germination rates were $40.0 \%$ and $2.67 \%$, respectively; however, the final germination rates of all seeds displayed no difference (Figure 8B,D). 
A

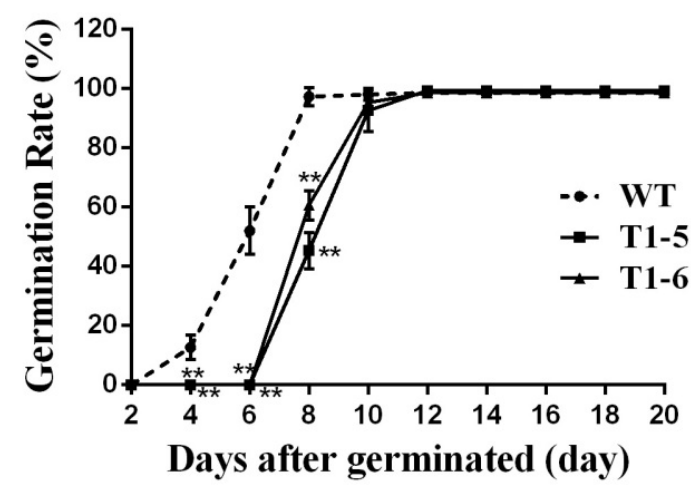

C

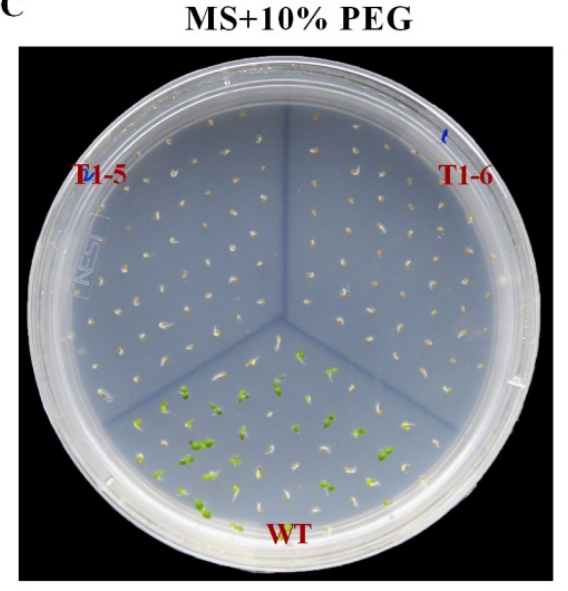

B

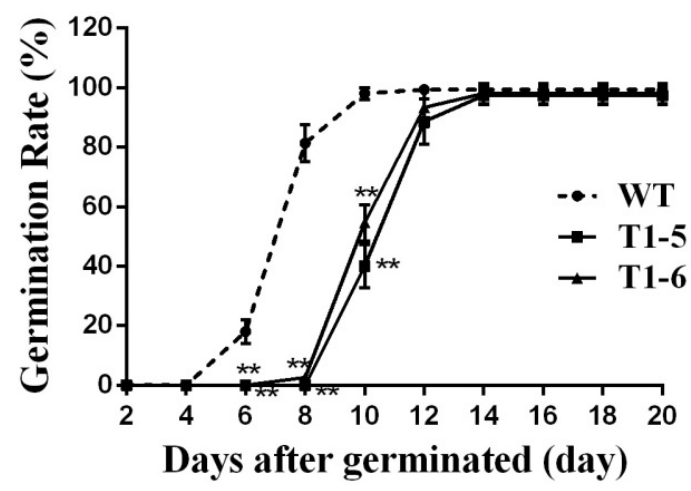

D

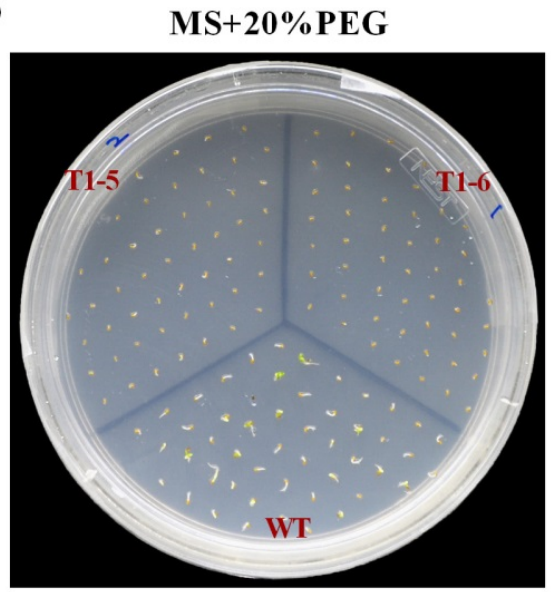

Figure 8. Effects of PEG application on germination rates between wild-type (WT) and transgenic plants. Fifty seeds of WT and T1 transgenic plants were sown on sterile MS solid medium supplemented with different concentrations of PEG $(\mathbf{A}, \mathbf{B})$. Values are means $\pm \mathrm{SD}(n=3)$. The photographs $(\mathbf{C}, \mathbf{D})$ were taken after being sown for 9 days. ${ }^{*}$ and ${ }^{* *}$ Significant at $p<0.05$ and $p<0.01$ compared with WT, respectively.

In the presence of $1 \mu \mathrm{M} A B A$, the OE plants displayed great inhibition of germination compared with the WT (Figure 9A,D). When the ABA concentration was increased to $2 \mu \mathrm{M}$, the inhibition was even greater (Figure 9B,E). The T1-5 and T1-6 seeds started to germinate at day 10, four days later than the WT, and their germination rates were $3.33 \%$ and $1.33 \%$, respectively, while that of the WT was $90.67 \%$. At the end of the treatment, the germination rates of T1-5 and T1-6 were $79.33 \%$ and $78.0 \%$, respectively, which were significantly lower than that of the WT $(98.67 \%)$. When the ABA concentration was increased to $4 \mu \mathrm{M}$, the final germination rates of T1-5 and T1-6 were just $30.0 \%$ and $16.0 \%$, respectively, which were dramatically lower than that of WT $(95.33 \%)$ (Figure 9C,F). 

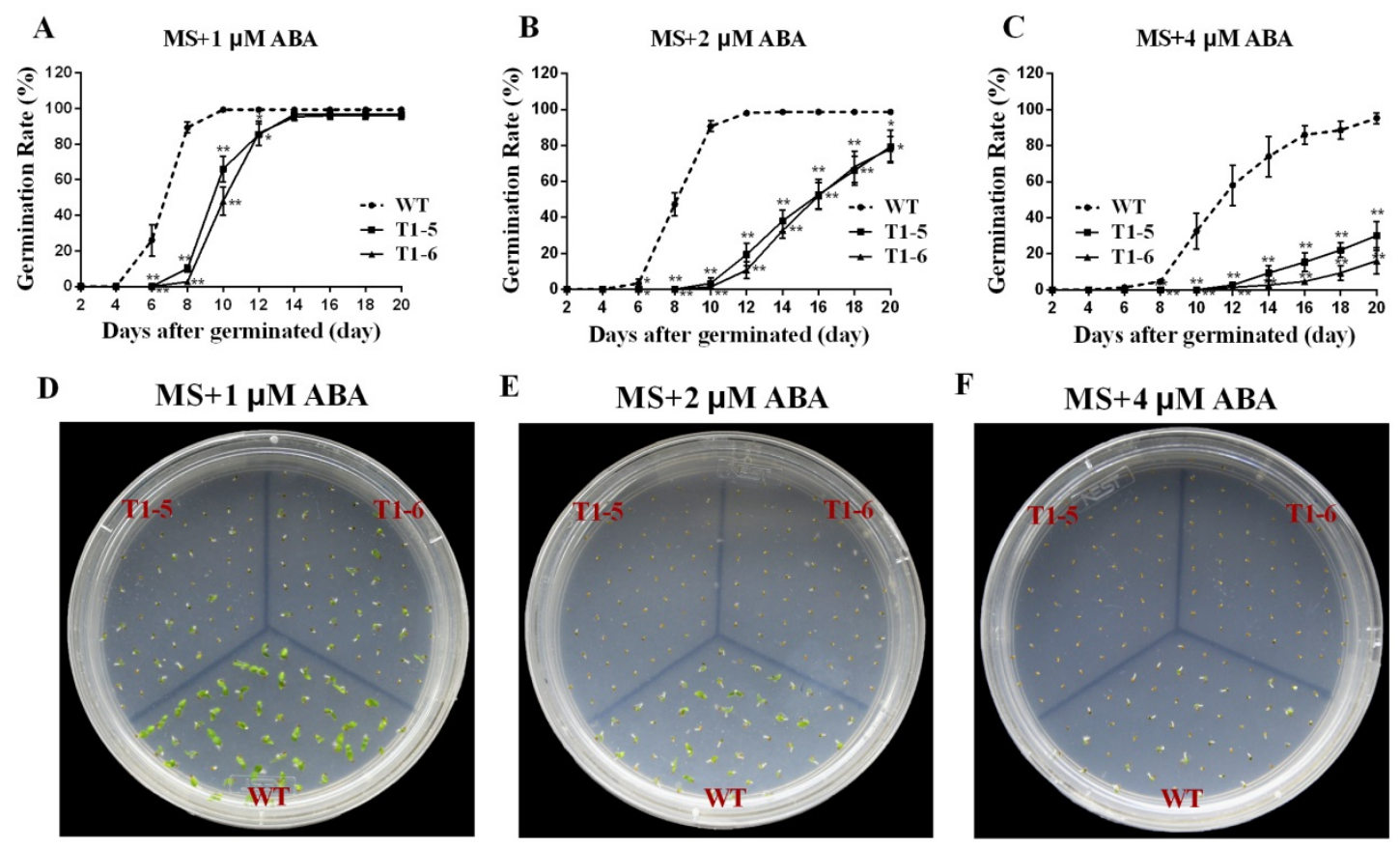

Figure 9. Effects of ABA application on germination rates between wild type (WT) and transgenic plants. Per 50 seeds of WT and T1 transgenic plants were sown on sterile MS solid medium supplemented with different concentrations of ABA $(\mathbf{A}-\mathbf{C})$. Values are means $\pm \mathrm{SD}(n=3)$. The photographs (B-D) were taken after being sown for $9 \mathrm{~d}$. * and ${ }^{* *}$ Significant at $p<0.05$ and $p<0.01$ compared with WT, respectively.

\section{Discussion}

Transcription factors play essential roles in regulating plant growth and development as well as responses to diverse abiotic stresses by activating or repressing related downstream genes [26]. With the completion of genome sequencing for more species, many major transcription factor families with large numbers of members have been identified and characterized in numerous plants, such as bHLH [27], MYB [28], and WRKY [29]. The functions of these transcription factors in growth, development, and stress responses have been studied extensively. However, no extensive studies have been done on the BPC family in recent years. Studies of BPC transcription factors have mainly focused on the regulation of plant growth and development $[12,14,15,25]$, and almost no research has been reported on their regulation of stress resistance. Additionally, functional studies of the BPC family have primarily been done in the model plants Arabidopsis $[12,14,15,25]$ and rice [22]; there is little information available about the BPC genes in other plant species.

In the present study, we identified and characterized four predicted BPC proteins in cucumber at the whole-genome level, and compared them with four watermelon, four melon, six cucurbita pepo, five grape, ten western balsam poplar, three common sunflower, seven Arabidopsis, four rice, and five tomato BPC proteins. Phylogenetic analysis classified these 52 BPC proteins into three groups (Figure 2), the same as in Arabidopsis [10]. Additionally, group I and group II contained similar members, whereas group III just contained two members, indicating that the BPC genes had diversified before various species diverged and that members in group III might be lost during the evolutionary process, however, the functions of these genes remain unclear. Here, the four CsBPC genes were classified into group I and group II, with each group containing two members. Gene structure (Figure $3 \mathrm{~A}$ ) and conserved motif (Figure 3B) analyses indicated that the CsBPC genes in the same group shared similar exon-intron and motif organizations, whereas members in different groups had differing exon-intron and motif compositions, which may suggest a closer evolutionary relationship between members of the same group and functional diversification among the members of different groups. Moreover, the two BPC 
groups showed a distinct difference in their N-terminal structural domains, which have been predicted to form zipper-like coiled-coil structures and may function as dimerization domains, protein-protein interactions domains, or nuclear and nucleolar localization signals [9,10,30]. Conversely, all four CsBPC members shared a highly conserved domain at their C-terminus that is important for DNA binding. The hallmark of this domain is the existence of five cysteine residues with defined positions and spacing $[9,10,30]$. These cysteines were previously believed to form a zinc finger-like structure for direct recognition of GAGA motifs [10]. However, the results of Theune et al.'s [31] research contradicted the suggestion of a zinc finger-like DNA-binding mechanism. Instead, they proposed that the conserved cysteines form inter- and intramolecular disulfide bonds to stabilize a parallel conformation of monomers, and that this conformation is required for neighboring GAGA motif recognition and binding.

Tissue-specific expression analysis is usually performed to predict the biological functions of genes in plant growth and development. Therefore, we investigated the expression of the four CsBPC genes by qRT-PCR in 12 different tissues. The results revealed that all four cucumber BPC genes were ubiquitously expressed in all the tissues tested, and that they shared the highest expression levels in seeds and the lowest levels in tendrils and stems (Figure 4), which may suggest a vital role for the CsBPCs in cucumber growth and development processes and, particularly, in seed development. Taking these results together, BPC transcription factors are essential for maintaining a wide range of normal growth and developmental processes, but further studies are needed to determine the functions of CsBPCs in regulating cucumber growth and development.

As there were few studies on BPCs in response to abiotic stresses and phytohormones, we did the expression analysis of CsBPCs under various stresses and hormones treatments. qRT-PCR showed that the transcriptional levels of all four CsBPC genes were induced by various abiotic stress treatments ( $\mathrm{NaCl}, \mathrm{PEG}$, cold, and heat) (Figure 5) and hormone treatments (ABA, SA, JA, ETH, 2,4-D, and GA) (Figure 6), indicating that abiotic stresses and hormones might be activators of the CsBPCs.

To further research the cellular functions of the CsBPCs, especially in plant responses to hyperosmotic stress, transgenic tobacco plants constitutively overexpressing CsBPC2, whose expression level increased the most under the majority of abiotic stress and hormone treatments, were generated. No apparent differences in seed germination rates or seedling size were observed when seeds of the WT and transgenic lines were germinated under normal growth conditions (Figure 7). However, when seeds of these plants were germinated on MS solid medium supplemented with different concentrations of $\mathrm{NaCl}$ (Figure 7) and PEG (Figure 8), the germination rates and times of the transgenic lines were significantly inhibited compared with those of the WT. Additionally, when seeds were germinated on MS solid medium supplemented with different concentrations of ABA, the inhibition was even more severe (Figure 9). Collectively, these results indicated that CsBPC2 plays a negative role in modulating seed germination under hyperosmotic conditions. CsBPC2 may also function in ABA-inhibited seed germination and hypersensitivity to ABA-mediated responses. The altered stress responses exhibited by $C S B P C 2$ transgenic seeds may be caused by changes in phytohormones levels. Numerous studies have demonstrated that plant hormones are critical for regulation of seed dormancy and germination [32,33]. For example, the plant hormones gibberellin [34,35], cytokinin [36], brassinosteroids [37], and ethylene [38] are positive regulators of seed germination, whereas abscisic acid is a negative regulator of seed germination $[39,40]$. A previous study confirmed a role for BPCS in the regulation of the cytokinin content in the meristem [14]. In Arabidopsis bpc1-1 bpc2 bpc3 triple mutants, the expression levels of both ISOPENTENYLTRANSFERASE 7 (IPT7) and ARABIDOPSIS RESPONSE REGULATOR 7 (ARR7), two genes involved in cytokinin biosynthesis and responsiveness, respectively [41-43], were upregulated, resulting in an increase in the cytokinin concentration in inflorescence meristems. Moreover, Arabidopsis bpc1-1 bpc2 bpc4 bpc6 quadruple mutants showed reduced sensitivity to ethylene responses, the lack of an apical hook, and delayed senescence [12]. The hormone-mediated regulatory mechanisms may be complex or there may be other signal perception or transduction pathways involved in seed germination regulation under hyperosmotic conditions; 
we need to research these issues in future studies. Additionally, further studies are needed to test the function of $C s B P C 2$ at the seedling stage in responses to abiotic stresses as genes can participate in different regulatory mechanisms at different growth stages and, thus, exhibit different functions. Understanding these matters will aid in understanding the BPC-mediated signaling cascades in plant resistance to stresses.

\section{Materials and Methods}

\subsection{Identification of BPC Gene Family Members in Cucumber}

Seven Arabidopsis BPC proteins sequences were downloaded from TAIR (http://www.arabidopsis. org) and the obtained sequences were used as queries to identify all GAGA-binding transcriptional activators in cucumber by searching against the Cucumber Genome Database (http://cucurbitgenomics. org/organism/2) with the BLASTP program and default E-value. All predicted cucumber BPC proteins were confirmed using the Pfam (http://pfam.xfam.org) [44] and SMART (http://smart.embl-heidelberg. de/) databases [45]. The amino acid lengths, chromosome locations, and strand directions of the BPC genes were also obtained from the databases. Physicochemical parameters, including the isoelectric point $(\mathrm{pI})$ and molecular weight $(\mathrm{kDa})$, were calculated using the compute $\mathrm{pI} / \mathrm{Mw}$ tool in ExPASy (http://web.expasy.org/compute_pi/). Subcellular location prediction was performed using the software CELLO 2.5 (http://cello.life.nctu.edu.tw/) [46]. The information on chromosome locations of the four BPC genes were drawn using MapInspect tool.

\subsection{Phylogenetic Gene Structure and Conserved Motif Analyses}

The sequences of the four cucumber, four watermelon, four melon, six cucurbita pepo, and seven Arabidopsis BPC genes were downloaded from the Cucumber (Chinese Long) v2 Genome Database (http: //cucurbitgenomics.org/organism/2), Watermelon (97103) v2 Genome Database (http://cucurbitgenomics. org/organism/21), Melon (DHL92) v3.6.1 Genome Database (http://cucurbitgenomics.org/organism/18), Cucurbita pepo (Zucchini) Genome Database (http://cucurbitgenomics.org/organism/14), and TAIR (https://www.arabidopsis.org/), respectively. The sequences of four rice, five grape, ten western balsam poplar, three common sunflower, and five tomato BPC proteins were obtained from UniProt (https: //www.uniprot.org/). All full-length protein sequences of cucumber, Arabidopsis, tomato, watermelon, melon, cucurbita pepo, grape, western balsam poplar, common sunflower, and rice were aligned using the Clustal W program with default parameters, and then an unrooted neighbor-joining phylogenetic tree was constructed using the MEGA7 software with 100 bootstrap replicates [47]. The exon-intron compositions of the cucumber BPC genes were predicted by comparing the CDS sequences with their corresponding genomic sequences using the online program GSDS 2.0 (http://gsds.cbi.pku.edu.cn/) [48]. The conserved motifs of the cucumber BPC proteins were identified using the online tool MEME (http://meme-suite.org/tools/meme) [49] with the following parameters: any number of repetitions site distribution, 5 motifs found, and minimum and maximum motif widths -6 and 50, respectively.

\subsection{Plant Material, Growth Conditions, and Treatments}

Cucumber (Cucumis sativus L. cv. 'changchunmici') seeds (saved by our laboratory) were germinated on moist gauze in an incubator at $28^{\circ} \mathrm{C}$ under dark conditions. The germinated seeds were sown in plastic plugs (32 holes) filled with nursery substrate (peat: vermiculite: perlite $=2: 1: 1$ ) in a climate chamber at The Institute of Vegetables and Flowers, Chinese Academy of Agricultural Sciences. When the seedlings were at the two-leaf-stage, they were transplanted into a greenhouse. When their fruits became ripe, samples of various tissues were collected, including fresh roots (R) and stems (S), top young leaves (YL), middle mature leaves (ML), basal old leaves (OL), blooming male flowers (MF), blooming female flowers with ovaries removed $(\mathrm{FF})$, ovaries $(\mathrm{O})$, tendrils $(\mathrm{T})$, around 10-day-old fruits (F), and seeds (FS) and pulp (FP) gathered from the mature fruits. All samples were immediately frozen in liquid nitrogen and stored at $-80^{\circ} \mathrm{C}$ for RNA extraction and tissue expression analysis. 
For different stress and phytohormone treatments, batches of five seedlings at the one-leaf-stage were transferred to a $5 \mathrm{~L}(33 \mathrm{~cm} \times 25 \mathrm{~cm} \times 11 \mathrm{~cm})$ plastic tank filled with an aerated complete nutrient solution (pH 6.0-6.5) containing: $\mathrm{Ca}\left(\mathrm{NO}_{3}\right)_{2} \cdot 4 \mathrm{H}_{2} \mathrm{O} 4 \mathrm{mM}, \mathrm{KNO}_{3} 6 \mathrm{mM}, \mathrm{MgSO}_{4} \cdot 7 \mathrm{H}_{2} \mathrm{O} 2 \mathrm{mM}, \mathrm{NH}_{4} \mathrm{H}_{2} \mathrm{PO}_{4}$ $1 \mathrm{mM}$, EDTA-FeNa $80 \mu \mathrm{M}, \mathrm{H}_{3} \mathrm{BO}_{3} 46.3 \mu \mathrm{M}, \mathrm{MnSO}_{4} \cdot \mathrm{H}_{2} \mathrm{O} 9.5 \mu \mathrm{M}, \mathrm{ZnSO}_{4} \cdot 7 \mathrm{H}_{2} \mathrm{O} 0.8 \mu \mathrm{M}, \mathrm{CuSO}_{4} \cdot 5 \mathrm{H}_{2} \mathrm{O}$ $0.3 \mu \mathrm{M}$, and $\left(\mathrm{NH}_{4}\right)_{6} \mathrm{Mo}_{7} \mathrm{O}_{2} \cdot 4 \mathrm{H}_{2} \mathrm{O} 0.02 \mu \mathrm{M}$. The experiment was carried out under normal conditions $\left(28^{\circ} \mathrm{C} / 14 \mathrm{~h}\right.$ light, $18^{\circ} \mathrm{C} / 10 \mathrm{~h}$ dark) in a climate chamber. When the cucumber seedlings were at the three-leaf-stage, $100 \mathrm{mM} \mathrm{NaCl}, 10 \%$ polyethylene glycol (PEG) 6000, $100 \mu \mathrm{mol}$ ABA, $100 \mu$ mol salicylic acid (SA), $100 \mu \mathrm{mol}$ jasmonic acid (JA), $50 \mu \mathrm{mol}$ ethephon (ETH), $50 \mu \mathrm{mol}$ 2,4-dichlorophenoxyacetic acid (2,4-D), and $50 \mu \mathrm{mol}$ gibberellin (GA) were added to the nutrient solution. For cold and heat treatments, cucumber seedlings were cultivated at $5{ }^{\circ} \mathrm{C}$ and $38^{\circ} \mathrm{C}$, respectively. Samples of cucumber seedlings were taken after $0,1,3,6,12$, and $24 \mathrm{~h}$ of the different treatments for gene expression analysis.

\subsection{Vector Construction and Tobacco Transformation}

Two primers were designed to amplify the CsBPC2 gene based on its CDS sequence (Additional file 2. S2). Then, the CsBPC2 CDS was inserted into the BamHI/PmlI restriction sites downstream of the 35S promoter of the vector 1305 (35S:CsBPC2) using In-Fusion technology. The construct was introduced into the Agrobacterium tumefaciens strain EHA105 for tobacco (Nicotiana tabacum cv. NC89) transformation using the leaf disc method [50]. Tobacco genomic DNA from young leaves was extracted for PCR confirmation using primers for Hyg (Additional file 2. S3) and CsBPC2 CDS amplification to determine whether CsBPC2 was integrated into the tobacco genome. Additionally, qRT-PCR was performed to further test the expression of $C S B P C 2$ in the transgenic tobacco plants using primers for CsBPC2, which is unique to cucumber (Additional file 2. S4).

\subsection{RNA Extraction and qRT-PCR Analysis}

Total RNA was extracted using an RNA prep pure Plant Kit (TANGEN) and first-strand cDNA was synthesized using a PrimeScript ${ }^{\mathrm{TM}} \mathrm{RT}$ reagent Kit with gDNA Eraser (Perfect Real Time) (TaKaRa) according to the manufacturer's instructions. Quantitative RT-PCR was performed following the instructions of the SYBR ${ }^{\circledR}$ Premix Ex Taq ${ }^{\mathrm{TM}}$ Kit (TaKaRa) on a Mx3000P real-time PCR instrument (Agilent). The experiments were performed with three biological replicates, each with three plants. Relative gene expression was calculated using the $2^{-\triangle \triangle C t}$ method [51]. The CsBPC specific primers used for expression pattern analysis in different tissues and under abiotic stress and hormone treatments are shown in Additional file 2. S1.

\subsection{Seed Germination of Transgenic Tobacco Plants under Hyperosmotic Stress Conditions}

Seeds of the wild-type (WT) and T1 progeny obtained from transgenic tobacco plants were germinated on sterile MS solid medium containing $30 \mathrm{~g} / \mathrm{L}$ sucrose. To test the effects of hyperosmotic stress or phytohormones on germination, 100 and $200 \mathrm{mM} \mathrm{NaCl}, 10 \%$ and 20\% PEG-6000, and 1, 2, and $4 \mu \mathrm{M}$ ABA were added to the medium. Germination rate assays were carried out on three replicates of 50 seeds. The seeds were geminated in an incubator $\left(26^{\circ} \mathrm{C} / 14 \mathrm{~h}\right.$ light, $10 \mathrm{~h}$ dark $)$ for 20 days.

\subsection{Statistical Analyses}

Values presented are means \pm standard deviation (SD) of three replicates. Statistical analyses were carried out by an analysis of variance (ANOVA) using SAS (SAS Institute, Cary, NC, USA) software. 


\section{Conclusions}

The ubiquitous expression of the four CsBPCs in various tissues perhaps to some extent implied they have crucial roles in regulating cucumber growth and development. Moreover, analysis of CsBPC expression under various abiotic stress ( $\mathrm{NaCl}, \mathrm{PEG}$, cold, and heat) and hormone (ABA, SA, JA, ETH, 2,4-D, and GA) treatments revealed that the CsBPCs respond to phytohormones and abiotic stresses. Additionally, tobacco plants overexpressing $C s B P C 2$ showed an inhibited germination phenotype when treated with $\mathrm{NaCl}$, PEG, and ABA, compared with the wild type. This further confirmed the regulatory function of the CsBPCs in stress and hormone responses. The present results reveal the potential roles of CsBPCs in cucumber development and abiotic stresses responses, and provide a basis for further functional studies of the BPC genes in cucumber and other plant species.

Supplementary Materials: Supplementary materials can be found at http://www.mdpi.com/1422-0067/20/20/ 5048/s1. Additional file 1: Sequences of CsBPC genes. A: The coding sequences of CsBPCs. B: The protein sequences of CsBPCs. C: The $2 \mathrm{~kb}$ genomic DNA sequences upstream of the initiation codon. Additional file 2: Sequences of the primers used in this study. Additional file 3: Confirmation of transgenic tobacco plants by PCR and qRT-PCR methods.

Author Contributions: X.Y., Y.L., and S.L. conceived and designed the research. S.L. performed the research. L.G. and C.H. made important comments on design of the trial, the article writing, and the revisions. L.M., B.H., Y.Y., and J.W. analyzed the data. S.L. wrote the first draft of the manuscript. X.Y. and Y.L. improved the first draft of the manuscript. All of the authors read and approved the final manuscript.

Funding: This work was financially supported by funds from the National Natural Sciences Foundations of China (No.31972480), the National Key Research and Development Plan of China (2018YFD0201207), the Earmarked fund for Modern Agro-industry Technology Research System in China (CARS-25-C-01), the Science and Technology Innovation Program of the Chinese Academy of Agricultural Sciences (CAASASTIP-IVFCAAS), and the Key Laboratory of Horticultural Crop Biology and Germplasm Innovation, Ministry of Agriculture, China. The funders played roles in the design of the study, the collection and analysis of data, and in writing the manuscript.

Conflicts of Interest: The authors declare no conflicts of interest.

\section{Abbreviations}

wt

qRT-PCR

PEG

MS

ABA wild-type

quantitative real-time polymerase chain reaction

polyethylene glycol

Murashige and Skoog

abscisic acid

\section{References}

1. Tanurdzic, M.; Banks, J.A. Sex-determining mechanisms in land plants. Plant. Cell 2004, 16, S61-S71. [CrossRef]

2. Zhang, B.C.; Tolstikov, V.; Turnbull, C.; Hicks, L.M.; Fiehn, O. Divergent metabolome and proteome suggest functional independence of dual phloem transport systems in cucurbits. Proc. Natl. Acad. Sci. USA 2010, 107, 13532-13537. [CrossRef]

3. Lee, S.H.; Singh, A.P.; Chung, G.C. Rapid accumulation of hydrogen peroxide in cucumber roots due to exposure to low temperature appears to mediate decreases in water transport. J. Exp. Bot 2004, 55, 1733-1741. [CrossRef]

4. Klobus, G.; Janicka-Russak, M. Modulation by cytosolic components of proton pump activities in plasma membrane and tonoplast from Cucumis sativus roots during salt stress. Physiol Plant. 2004, 121, 84-92. [CrossRef]

5. Zhong, M.; Yuan, Y.H.; Shu, S.; Sun, J.; Guo, S.R.; Yuan, R.N.; Tang, Y.Y. Effects of exogenous putrescine on glycolysis and Krebs cycle metabolism in cucumber leaves subjected to salt stress. Plant. Growth Regul 2016, 79, 319-330. [CrossRef] 
6. Janoudi, A.K.; Widders, I.E.; Flore, J.A. Water deficits and environmental factors affect photosynthesis in leaves of cucumber (Cucumis sativus). J. Am. Soc. Hortic Sci. 1993, 118, 366-370. [CrossRef]

7. Klein, E.; Katan, J.; Gamliel, A. Soil suppressiveness by organic amendment to Fusarium disease in cucumber: effect on pathogen and host. Phytoparasitica 2016, 44, 239-249. [CrossRef]

8. Sangwan, I.; O'Brian, M.R. Identification of a soybean protein that interacts with GAGA element dinucleotide repeat DNA. Plant. Physiol. 2002, 129, 1788-1794. [CrossRef]

9. Santi, L.; Wang, Y.M.; Stile, M.R.; Berendzen, K.; Wanke, D.; Roig, C.; Pozzi, C.; Muller, K.; Muller, J.; Rohde, W.; et al. The GA octodinucleotide repeat binding factor BBR participates in the transcriptional regulation of the homeobox gene Bkn3. Plant. J. 2003, 34, 813-826. [CrossRef]

10. Meister, R.J.; Williams, L.A.; Monfared, M.M.; Gallagher, T.L.; Kraft, E.A.; Nelson, C.G.; Gasser, C.S. Definition and interactions of a positive regulatory element of the Arabidopsis INNER NOOUTER promoter. Plant. J. 2004, 37, 426-438. [CrossRef]

11. Kooiker, M.; Airoldi, C.A.; Losa, A.; Manzotti, P.S.; Finzi, L.; Kater, M.M.; Colombo, L. BASIC PENTACYSTEINE1, a GA binding protein that induces conformational changes in the regulatory region of the homeotic Arabidopsis gene SEEDSTICK. Plant. Cell 2005, 17, 722-729. [CrossRef]

12. Monfared, M.M.; Simon, M.K.; Meister, R.J.; Roig-Villanova, I.; Kooiker, M.; Colombo, L.; Fletcher, J.C.; Gasser, C.S. Overlapping and antagonistic activities of BASIC PENTACYSTEINE genes affect a range of developmental processes in Arabidopsis. Plant. J. 2011, 66, 1020-1031. [CrossRef]

13. Simonini, S.; Roig-Villanova, I.; Gregis, V.; Colombo, B.; Colombo, L.; Kater, M.M. Basic pentacysteine proteins mediate MADS domain complex binding to the DNA for tissue-specific expression of target genes in Arabidopsis. Plant. Cell 2012, 24, 4163-4172. [CrossRef]

14. Simonini, S.; Kater, M.M. Class I BASIC PENTACYSTEINE factors regulate HOMEOBOX genes involved in meristem size maintenance. J. Exp. Bot. 2014, 65, 1455-1465. [CrossRef]

15. Hecker, A.; Brand, L.H.; Peter, S.; Simoncello, N.; Kilian, J.; Harter, K.; Gaudin, V.; Wanke, D. The Arabidopsis GAGA-Binding Factor BASIC PENTACYSTEINE6 Recruits the POLYCOMB-REPRESSIVE COMPLEX1 Component LIKE HETEROCHROMATIN PROTEIN1 to GAGA DNA Motifs. Plant. Physiol 2015, 168, 1013-1024. [CrossRef]

16. Anusak, P.; Ditta, G.S.; Beth, S.; Liljegren, S.J.; Elvira, B.; Ellen, W.; Yanofsky, M.F. Assessing the redundancy of MADS-box genes during carpel and ovule development. Nature 2003, 424, 85-88.

17. Rebecca, F.; Anusak, P.; Raffaella, B.; Maarten, K.; Lorenzo, B.; Gary, D.; Yanofsky, M.F.; Kater, M.M.; Lucia, C. MADS-box protein complexes control carpel and ovule development in Arabidopsis. Plant. Cell 2003, 15, 2603-2611.

18. Berger, N.; Dubreucq, B.; Roudier, F.; Dubos, C.; Lepiniec, L. Transcriptional regulation of Arabidopsis LEAFY COTYLEDON2 involves RLE, a cis-element that regulates trimethylation of histone H3 at lysine-27. Plant. Cell 2011, 23, 4065-4078. [CrossRef]

19. Stone, S.L.; Kwong, L.W.; Yee, K.M.; Pelletier, J.; Lepiniec, L.; Fischer, R.L.; Goldberg, R.B.; Harada, J.J. LEAFY COTYLEDON2 encodes a B3 domain transcription factor that induces embryo development. Proc. Natl. Acad. Sci. USA 2001, 98, 11806-11811. [CrossRef]

20. Kroj, T.; Savino, G.; Valon, C.; Giraudat, J.; Parcy, F. Regulation of storage protein gene expression in Arabidopsis. Development 2003, 130, 6065-6073. [CrossRef]

21. Mu, Y.; Liu, Y.M.; Bai, L.Q.; Li, S.Z.; He, C.X.; Yan, Y.; Yu, X.C.; Li, Y.S. Cucumber CsBPCs regulate the expression of CsABI3 during seed germination. Front. Plant. Sci. 2017, 8, 459. [CrossRef]

22. Gong, R.; Cao, H.; Zhang, J.; Xie, K.; Wang, D.; Yu, S. Divergent functions of the GAGA-binding transcription factor family in rice. Plant. J. 2018, 94, 32-47. [CrossRef]

23. Peng, L.T.; Shi, Z.Y.; Li, L.; Shen, G.Z.; Zhang, J.L. Overexpression of transcription factor OsLFL1 delays flowering time in Oryza sativa. J. Plant. Physiol 2008, 165, 876-885. [CrossRef]

24. Peng, L.T.; Shi, Z.Y.; Li, L.; Shen, G.Z.; Zhang, J.L. Ectopic expression of OsLFL1 in rice represses Ehd1 by binding on its promoter. Biochem. Biophys. Res. Commun. 2007, 360, 251-256. [CrossRef]

25. Shanks, C.M.; Hecker, A.; Cheng, C.Y.; Brand, L.; Collani, S.; Schmid, M.; Schaller, G.E.; Wanke, D.; Harter, K.; Kieber, J.J. Role of BASIC PENTACYSTEINE transcription factors in a subset of cytokinin signaling responses. Plant. J. 2018, 95, 458-473. [CrossRef] 
26. Wu, S.; Gallagher, K.L. Transcription factors on the move. Curr. Opin. Plant. Biol. 2012, 15, 645-651. [CrossRef]

27. Mao, K.; Dong, Q.; Li, C.; Liu, C.; Ma, F. Genome wide identification and characterization of apple bHLH transcription factors and expression analysis in response to drought and salt stress. Front. Plant. Sci. 2017, 8, 480. [CrossRef]

28. Wang, Y.; Zhan, D.F.; Li, H.L.; Guo, D.; Zhu, J.H.; Peng, S.Q. Transcriptome-wide identification and characterization of MYB transcription factor genes in the laticifer cells of Hevea brasiliensis. Front. Plant. Sci. 2017, 8, 1974. [CrossRef]

29. Xie, T.; Chen, C.; Li, C.; Liu, J.; Liu, C.; He, Y. Genome-wide investigation of WRKY gene family in pineapple: evolution and expression profiles during development and stress. BMC Genomics 2018, 19, 490. [CrossRef]

30. Wanke, D.; Hohenstatt, M.L.; Dynowski, M.; Bloss, U.; Hecker, A.; Elgass, K.; Hummel, S.; Hahn, A.; Caesar, K.; Schleifenbaum, F.; et al. Alanine zipper-like coiled-coil domains are necessary for homotypic dimerization of plant GAGA-factors in the nucleus and nucleolus. PLoS ONE 2011, 6, e16070. [CrossRef]

31. Theune, M.L.; Hummel, S.; Jaspert, N.; Lafos, M.; Wanke, D. Dimerization of the BASIC PENTACYSTEINE domain in plant GAGA-factors is mediated by disulfide bonds and required for DNA-binding. J. Adv. Plant. Biol. 2017, 1, 26-39. [CrossRef]

32. Kucera, B.; Cohn, M.A.; Leubner-Metzger, G. Plant hormone interactions during seed dormancy release and germination. Seed Sci. Res. 2005, 15, 281-307. [CrossRef]

33. Warpeha, K.M.; Montgomery, B.L. Light and hormone interactions in the seed-to-seedling transition. Environ. Exp. Bot. 2016, 121, 56-65. [CrossRef]

34. Gupta, R.; Chakrabarty, S.K. Gibberellic acid in plant: still a mystery unresolved. Plant. Signal. Behav. 2013, 8. [CrossRef]

35. Hedden, P.; Thomas, S.G. Gibberellin biosynthesis and its regulation. Biochem. J. 2012, 444, 11-25. [CrossRef]

36. Perilli, S.; Moubayidin, L.; Sabatini, S. The molecular basis of cytokinin function. Curr. Opin. Plant. Biol. 2010, 13, 21-26. [CrossRef]

37. Clouse, S.D. Brassinosteroids. The Arabidopsis Book 2011, 9, e0151. [CrossRef]

38. Corbineau, F.; Xia, Q.; Bailly, C.; El-Maarouf-Bouteau, H. Ethylene, a key factor in the regulation of seed dormancy. Front. Plant. Sci. 2014, 5, 539. [CrossRef]

39. Sakata, Y.; Komatsu, K.; Takezawa, D. ABA as a universal plant hormone. Progress Botany 2014, 75, 57-96.

40. Cutler, S.R.; Rodriguez, P.L.; Finkelstein, R.R.; Abrams, S.R. Abscisic acid: Emergence of a core signaling network. Annu. Rev. Plant. Biol. 2010, 61, 651-679. [CrossRef]

41. Kakimoto, T. Identification of plant cytokinin biosynthetic enzymes as dimethylallyl diphosphate: ATP/ADP isopentenyltransferases. Plant. Cell Physiol. 2001, 42, 677-685. [CrossRef]

42. Buechel, S.; Leibfried, A.; To, J.P.C.; Zhao, Z.; Andersen, S.U.; Kieber, J.J.; Lohmann, J.U. Role of A-type ARABIDOPSIS RESPONSE REGULATORS in meristem maintenance and regeneration. Eur. J. Cell Biol. 2010, 89, 279-284. [CrossRef]

43. Zhong, Z.; Andersen, S.U.; Karin, L.; Karel, D.; Andrej, M.; Schultheiss, S.J.; Lohmann, J.U. Hormonal control of the shoot stem-cell niche. Nature 2010, 465, 1089-1092.

44. Bateman, A.; Birney, E.; Durbin, R.; Eddy, S.R.; Howe, K.L.; Sonnhammer, E.L. The Pfam protein families database. Nucleic Acids Res. 2000, 28, 263-266. [CrossRef]

45. Letunic, I.; Bork, P. 20 years of the SMART protein domain annotation resource. Nucleic Acids Res. 2018, 46, D493-D496. [CrossRef]

46. Yu, C.S.; Chen, Y.C.; Lu, C.H.; Hwang, J.K. Prediction of protein subcellular localization. Proteins 2006, 64, 643-651. [CrossRef]

47. Wang, P.; Wang, S.; Chen, Y.; Xu, X.; Guang, X.; Zhang, Y. Genome-wide Analysis of the MADS-Box Gene Family in Watermelon. Comput. Biol. Chem. 2019, 80, 341-350. [CrossRef]

48. Hu, B.; Jin, J.; Guo, A.Y.; Zhang, H.; Luo, J.; Gao, G. GSDS 2.0: an upgraded gene feature visualization server. Bioinformatics 2015, 31, 1296-1297. [CrossRef]

49. Bailey, T.L.; Boden, M.; Buske, F.A.; Frith, M.; Grant, C.E.; Clementi, L.; Ren, J.; Li, W.W.; Noble, W.S. MEME SUITE: tools for motif discovery and searching. Nucleic Acids Res. 2009, 37, W202-W208. [CrossRef] 
50. Horsch, R.B.; Fry, J.E.; Hoffmann, N.L.; Eichholtz, D.; Rogers, S.G.; Fraley, R.T. A simple and general method for transferring genes into plants. Science 1985, 227, 1229-1231.

51. Livak, K.J.; Schmittgen, T.D. Analysis of relative gene expression data using real-time quantitative PCR and the $2^{-\Delta \Delta C T}$ Method. Methods 2001, 25, 402-408. [CrossRef]

(C) 2019 by the authors. Licensee MDPI, Basel, Switzerland. This article is an open access article distributed under the terms and conditions of the Creative Commons Attribution (CC BY) license (http://creativecommons.org/licenses/by/4.0/). 